\title{
Comparing prevalence of sexual dysfunctions between narcissists and healthy persons
}

\author{
Maryam Heravi $^{1}$, Afshin Salahian ${ }^{2}$ \\ 1-PhD Student, Department of Psychology, Science and Research Branch, Islamic Azad University, Tehran, Iran. \\ 2- Assistant Professor, Department of Psychology, Payame Noor University (PNU), Tehran, Iran (Corresponding \\ Author). $\quad$ E-mail: Salahian2020@gmail.com
}

Received: 28/10/2021 Accepted: 01/01/2022

\begin{abstract}
Introduction: Sexual dysfunction is considered a common sexual problem affecting different aspects of life, and it seems to be rooted in individual's personality.

Aim: This paper aims to compare prevalence of sexual dysfunctions between those with narcissistic personality disorder (NPD) and healthy persons.

Method: This is a causal - comparative research. To do so, 700 males and females from Tehran City were screened in 2021, among them 120 persons were diagnosed with NPD and 41 persons were selected through convenience sampling as individuals with disorder. Data of 40 healthy persons were analyzed for comparative purposes. Millon Clinical Multiaxial Inventory (MCMI3), Female Sexual Functions Index (FSFI) and International Index of Erectile Function (ILEF) were used. Data were analyzed by comparing two independent groups in SPSS, Version 26.

Results: In females, there were no significant differences in sexual function $(\mathrm{t}=1.011, \mathrm{P}=0.320)$, moisture $(\mathrm{t}=0.537, \mathrm{P}=0.595)$, orgasm $(\mathrm{t}=-0.539, \mathrm{P}=0.594)$, sexual pleasure $(\mathrm{t}=0.164, \mathrm{P}=0.871)$ and pain $(\mathrm{t}=0.999, \mathrm{P}=0.327)$ between narcissists and healthy persons. Difference in sexuality $(\mathrm{t}=2.289, \mathrm{P}<0.05)$ and arousal $(\mathrm{t}=2.107, \mathrm{P}<0.05)$ in healthy persons was more significant than narcissists. Moreover, in males, the difference in sexual function $(\mathrm{t}=7.545, \mathrm{P}<0.001)$, sexuality $(\mathrm{t}=12.871, \mathrm{P}<0.001)$ and erection $(\mathrm{t}=4.832, \mathrm{P}<0.001)$ in healthy persons was more significant than narcissists, and orgasm $(\mathrm{t}=-3.426, \mathrm{P}<0.01)$ in narcissists was less than in healthy persons. However, there was no significant difference between sexual pleasure in both groups $(\mathrm{t}=-0.866$, $\mathrm{P}=0.393$ ).
\end{abstract}

Conclusion: The results show that prevalence of sexual dysfunctions in narcissists is more than healthy persons. Therefore, it is recommended that counselors and psychologists consider personality traits in diagnosis and treatment of sexual disorders.

Keywords: Narcissistic personality disorder (NPD), Sexual dysfunction, Orgasm, Screening

How to cite this article: Heravi M, Salahian A. Comparing prevalence of sexual dysfunctions between narcissists and healthy persons. Shenakht Journal of Psychology and Psychiatry. 2022; 8 (6): 56-68 .URL: http://shenakht.muk.ac.ir/article-1-1206-en.pdf

Copyright $\odot 2018$ the Author (s). Published by Kurdistan University of Medical Sciences. This is an open access article distributed under the terms of the Creative Commons Attribution-Non Commercial License 4.0 (CCBY-NC), where it is permissible to download, share, remix, transform, and buildup the work provided it is properly cited. The work cannot be used commercially without permission from the journal. 


\title{
مقايسه ميزان شيوع اختلالات عملكرد جنسى در مبتلايان به اختلال شخصيت خودشيفته و افراد سالم
}

\author{
مريم هروى '، افشين صلاحيان' \\ ا.دانشجوى دكتراى، گروه روانشناسى، واحد علوم و تحقيقات، دانشكاه آزاد اسلامى، تهران، ايران.
}

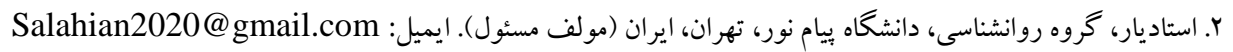

مقدمه: اختلال عملكرد جنسى يكى از مشكلات شايع جنسى است كه بر ابعاد مختلف زندكى اثر گذار است و ريشه در شخصيت فرد دارد.

هدف: اين مقاله با هدف مقايسه ميزان شيوع اختلالات عملكرد جنسى در مبتلايان به اختلال شخصيت خودشيفته و افراد سالم انجام

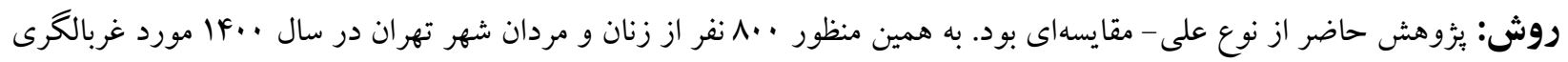

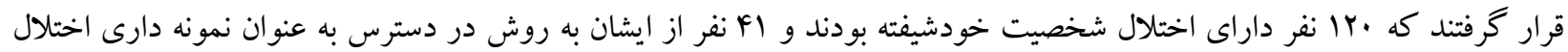

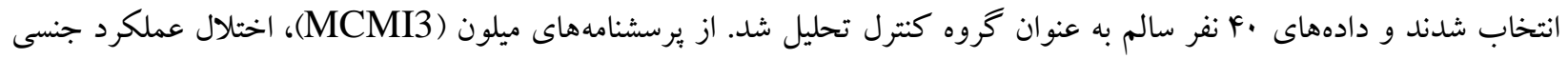

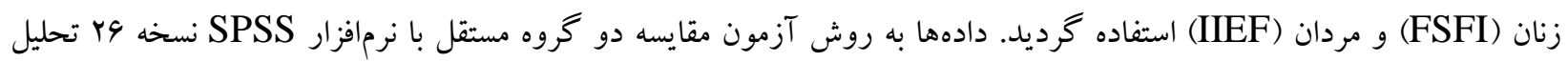

يافته ها: در زنان تفاوت عملكرد جنسى (••P=/rY)، رضايتمندى (t=/AVI)

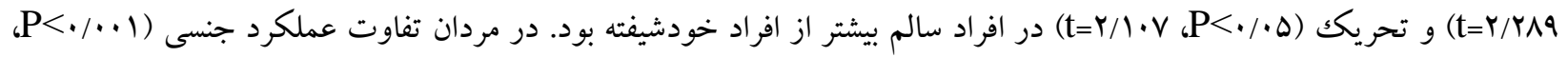

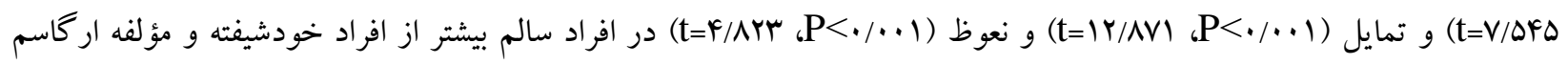
(t=-r/Frצ در افراد خودشيفته كمتر از افراد سالم بود؛ اما تفاوت رضايت جنسى در افراد خودشيفته و افراد سالم معنادار

$$
\text { نبود (t=- (1/199، }
$$

نتيجه كيرى: نتايج يافتها گوياى آن بود كه شيوع اختلالات عملكرد جنسى در افراد خودشيفته بيشتر از افراد سالم است. در اين راستا

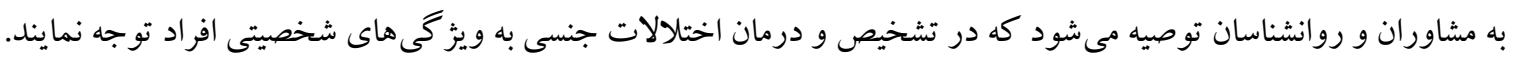
كليدوازهها: اختلال شخصيت خودشيفته، اختلال عملكرد جنسى، ار كاسم، غربالكرى 
خودشيفتكى تاريخجه كستردهاى هم در موزه روانشناسى شخصيت و هم در حوزه روانشناسى بالينى دارد؛ خودشيفتكى اولين بار به عنوان يكك سازه بالينى با نام نوعى اختلال از نوشتهاى فرويد (19|f) برخاسته

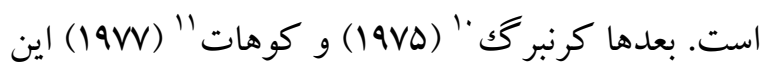
ديد گاه بالينى را در مورد خودشيفتخى ادامه دادند كه با فاصله اندكى بعد از آن منجر به ورود آن در راهنماى تشخيصى ويرايش سوم به عنوان يكى از اختلالات شخصيت با نام اختلال شخصيت خودشيفته شد (نيناديك، (Y.Y.Y). به باور كوهات فرد دجار اختلال شخصيت خودشيفته در ظاهر خود والا بينى جشمگير، خودشيفتكى باور و خيالات مربوط به موفقيت نامحدود دارند؛ اما اين ويز گىها در حقيقت عزت نفسى بسيار شكننده را ينهان مى كنند (ويليام، كسينى، موسلى، فراتينى و رونينگستام بام، '، (Y.Y.Y). اين افراد انتظار دارند بدون كسب دستاورد خاصى از سوى ديگران تحسين شوند و شكست در دريافت اين تحسينهاى خارجى منجر به ملال، خلأ و بىقرارى در آنها مىشود. در عين حال اين افراد وابستكى در روابط را تقبيح كرده و به خاطر خودكفا

بودن به خود مىبالند (ذبيحى فرد و صلاحيان، . . IF).

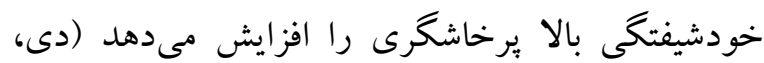

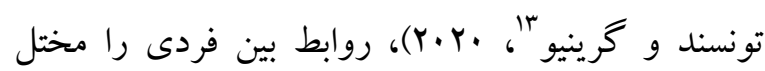
مى كند (ميلر، ويديخر و كميل" رضايت و كيفيت زندگى (مارتين، ولكات، كلارك، بارتون و هيكلينگ ه'، سا •Y)، احتمال آسيب رساندن به خود و اقدام به خود كشى همراه است (راتينگستم،

${ }^{10}$ - Kernberg

${ }^{11}$ - Kohut

${ }^{12}$ - Williams, Casini, Moselli, Frattini \& Ronningstam

${ }^{13}$ - Day, Townsend \& Grenyer

${ }^{14}$ - Miller, Widiger \& Campbell

${ }^{15}$ - Martin, Walcott, Clarke, Barton \& Hickling
مقلمهه

شخصيت' شامل الكوهاى ثابت فكرى، عاطفى و رفتارى

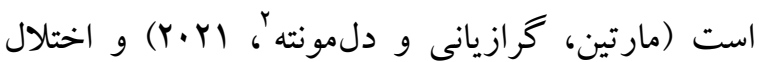
شخصيت آ الخويى بايدار از تجربيات درونى و رفتار است كه بهطور قابلتوجهى از انتظارات فرهنگى فرد انحراف داشته، فراگير و انعطافنايذير بوده و در طول زمان داراى ثبات است و منجر به بريشانى و هيجانى با دوام در فرد مبتلا و يا اطر افيانش مى گردد و كيفيت زندگى و كار فرد و روابط بين فردى وى را با مشكل روبرو مى كند (دونالد

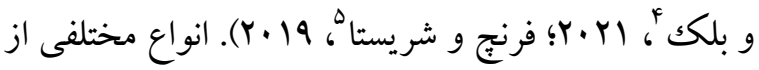
اختلالات شخصيت وجود دارند كه براساس مشخصهها و علائم مشابه در سه دسته كلى گروهبندى مىشوند كه دسته اول با شكك، دسته دوم با احساسات و تكانهها و دسته سوم با اضطراب مرتبط هستند (نيناديكك? (Y.Y.). اختلال شخصيت خودشيفته ليكى از اختلالات دسته دوم (خوشه ب) است كه براساس ينجمين نسخه راهنماى تشخيصى و آمارى اختلالات روانى داراى نرخ شيوع بالاى IV درصد در جمعيت بالينى و 9/Y-· درصد در جمعيت عمومى است (راتينگستم؟؛ 19 (Y). در عين حال

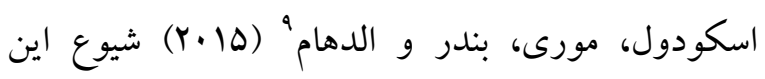
اختلال را به دليل ماهيت مزمن بيشتر از آنجه در بنجمين نسخه راهنماى تشخيصى و آمارى اختلالات روانى آمده است بر آورد كردهاند (اسكودول، مورى، بندر و الدهام،

\footnotetext{
1. Personality

2- Martin, Graziani \& Del-Monte

3 - Personality Disorder

4- Donald \& Black

5 - French \& Shrestha

${ }^{6}$ - Nenadic

7- Narcissistic Personality Disorder (NPD)

${ }^{8}$ - Ronningstam

${ }^{9}$ - Skodol, Morey, Bender \& Oldham
} 
در رابطه جنسى از يكك فرد داراى اختلال شخصيت خودشيفته تعريف و تمجيد شود كه او بهترين شريك جنسى است، وى بهترين حالت خود را به نمايش خواهد كذاشت؛ اما اكر اين تعريف و تمجيدها در رابطه براى بهرئ افراد داراى اختلال شخصيت خودشيفته فراهم نشود كه

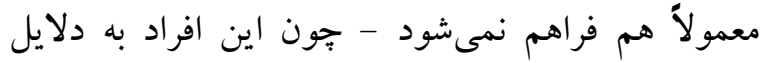
فوقالذكر شركاى جنسى خوبى نبوده و شر كاى جنسى خود را ناكام مى گذارند- سعى مى كند به سرعت از رابطه

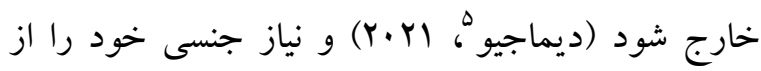

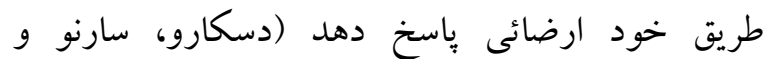

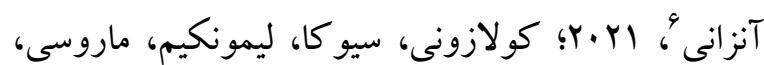
مولايولى، دى سانته و جانينى ل، IV IV). علىرغم اهميت موضوع عملكرد جنسى مطلوب در كيفيت زندكى فردى و اجتماعى، اطلاعات كمى در زمينه ميزان بروز اختلالات عملكرد جنسى وجود دارد (مكك كيب، شارليڤ، لويس، آتالا، بالن، فيشر و و

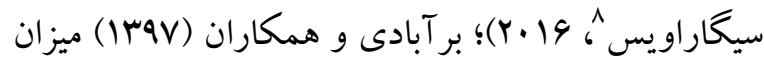
شيوع اختلالات جنسى در زنان را بين ·ب تا •م درصد كزارش كرده است (بر آبادى، آكاه، قسامى، رحيمى و

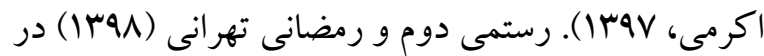
يثزوهش خود نشان دادند كه شيوع اختلال عملكرد جنسى در مردان حدود \& F/ الى اس/· برآورد شده است (رستمى دوم و رمضانى تهرانى، وه|1). همجنين در

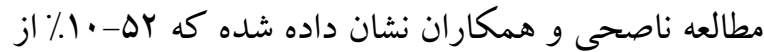
مردان و سو-هاץ/ از زنان دجار اختلال عملكرد جنسى هستند (ناصحى، رئيسى، قائلى، امينى، يحيوى، عرب-

$$
\text { خردمند و همكاران، و94) (1). }
$$

5 - Dimaggio

6. Decaro, Di Sarno \& Anzani

7. Collazzoni, Ciocca, Limoncin, Marucci, Mollaioli, Di Sante \& Jannini

${ }^{8}$ - McCabe, Sharlip, Lewis, Atalla, Balon, Fisher \& Segraves r|r. (Y). افزايش سطح خودشيفتگى در افراد به مشكلات اجتماعى مانند تجاوز و خشونت منجر شده (نيناديك، (Y.Y. ) و منجر به كاهش لذت واقعى مى كردد (كويرتزمايدان'، IV. IV). افراد مبتلا به اختلال شخصيت خودشيفته در برقرارى ارتباط ميان فردى دجار مشكلاتى مىشوند من جمله روابطى كه با تجربيات جنسى مرتبطاند

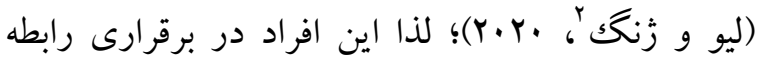
دوستانه و خصو صاً رابطه جنسى بسيار مشكل يسند هستند

$$
\text { (ذبيحىفرد و صلاحيان، ... (IF). }
$$

براساس تحقيقات اخير روابط جنسى نقش مهمى را در بيشتر نظريههاى خودشيفتكى ايفا مى كند (كلاين و و

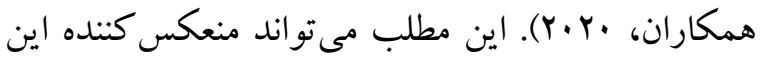
باشد كه تمايل افراد خودشيفته جهت مشاركت در رابطه جنسى صرفاً برآوردن نياز خود براى تأييد خود است

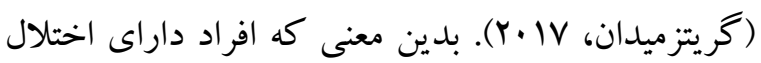
شخصيت خودشيفته تمايل دارند كه روابط جنسى و احساسى را به عنوان فرصتهايى بييند براى تقويت حس

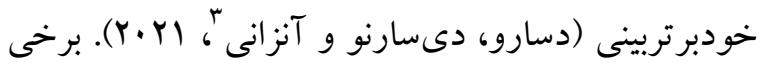
تحقيقات نيز گوياى آن است كه اين افراد در بي يافتن شر كاى جنسى صرفاً به جهت ارضاء نيازهاى خود مى باشند و در اين راستا از داشتن شر كاى جنسى متعدد ابايى

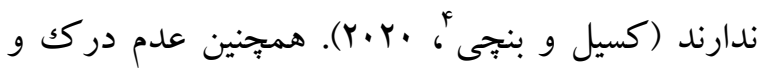
همدلى در افراد داراى اختلال شخصيت خودشيفته منجر به بروز مشكلات و سوءتفاهمهايى در روابط جنسى اين افراد شده كه مىتواند عاملى مهم و تعيين كننده در تمايل بيشتر اين افراد به خود ارضائى در مقايسه با جمعيت بهنجار است (ذبيحى و صلاحيان، ..F.|F). درصورتى كه

\footnotetext{
1- Gewirtz-Maydan

2- Liu \& Zheng

3- Decaro, Di Sarno \& Anzani

4- Casale \& Banchi
} 
آن بى جواب بودند، از روند تحقيق كنار كذاشته شدند.

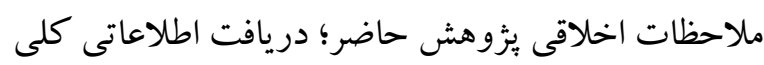
بلهورت كتبى و محرمانه بودن اطلاعات و عدم ثبت نام

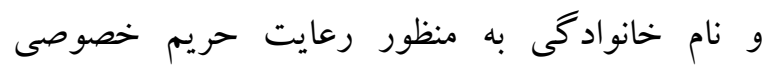
شر كت كنند كان بود.

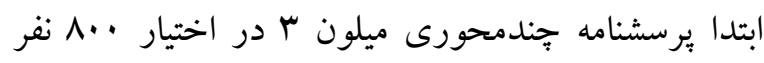

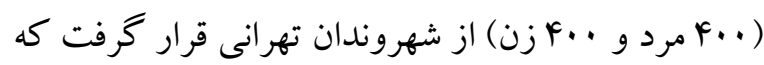
Vو VF اعتبار شناخته شده و از روند تحقيق كنار كذاشته شد. نفر (9 مرد و rا زن) از نمونه نمرات بالاتر از نرخ بايه كسب كرده بودند؛ لذا داراى اختلال شخصيت (VD) خودشيفته تشخيص داده شدند. از بين افرادى كه نمرات يايينتر از نرخ بايه (• •ه) كسب كرده بودند فاقد اختلال شخصيت خودشيفته تشخيص داده شده و •F نفر ( •r مرد و ·r ز زن) به عنوان نمونه سالم انتخاب شدند كه دادههاى ايشان به عنوان گرووه كنترل تحليل شد. برسشنامههاى اختلال عملكرد جنسى زنان و مردان براى دو گروه ارسال شد. به منظور تجزيه و تحليل دادهها در بخش توصيفى از شاخص هاى مركزى و براكندگى و در بخش استنباطى از روش آزمون t-test دو گروه مستقل استفاده شد. براى مرى بررسى بيشفرض إنها آزمون لوين و و آزمون كولمو گروف اسميرونف و براى بررسى تفاوتهاى دو كروه از آزمون t-test دو گروه مستقل استفاده شد. محاسبات آمارى با بهره گيرى از نرمافزار SPSS نسخه

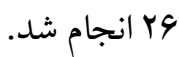

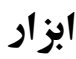

با توجه به تأثير انكار ناشدنى عملكرد جنسى بر جنبههاى مختلف زندكى فرد، برداختن به آن ضرورت مى يابد. در حالى كه علىرغم شيوع بالا و ماهيت تأثير گذار اختلالات كاركرد جنسى، مطالعات اندكى در زمينه محتواى روانى، فيزيولوزيكى و فرهنكى اختلال عملكرد جنسى در دسترس است و با وجود شواهدى كه مبين بروز اختلال در عملكرد جنسى افراد مبتلا به اختلال شخصيت خودشيفته وجود دارد، تاكنون يزوهشى با محوريت شيوع اختلال كاركرد جنسى در مبتلايان به اختلال شخصيت خودشيفته صورت نكرفته و خلأ بزوهشى در اين زمينه به وضوح احساس مىشود. در اين راستا بزوهش حاضر با هدف مقايسه ميزان شيوع اختلال عملكرد جنسى در مبتلايان به اختلال شخصيت خودشيفته و افراد سالم انجام شد. يثزوهش حاضر توصيفى از نوع على - مقايسهاى است. براى اين منظور . ․ نفر از زنان و مردان شهر تهران در سال . IF توسط برسشنامه جند محورى ميلون ب غربالكرى شدند و ·rl انفر داراى اختلال شخصيت خودشيفته

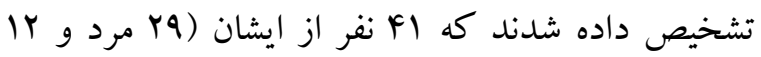
زن) به روش در دسترس به عنوان نمونه انتخاب شدند و

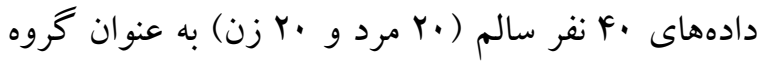
كنترل تحليل شد. معيار ورود به نمونه مقيم تهران، دامنه سنى ·r ت تا .9 سال، عدم ابتلا به بيمارى خاص و عدم مصرف دارو بود كه بهصورت آكاهانه و با رضايت كامل در ئزوهش شركت كردند. معيار خروج عدم تمايل به ادامه حضور در طرح يثوهشى بود و زيرسشنامهاى مخدوش و برسشنامههايى كه بيش از ها؟ از سؤالهاى 
سؤال است كه در طيف ليكرت بنج درجهاى (از تقريباً

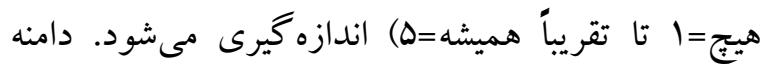
نمره اين مقياس از حداقل 19 تا حداكثر هو است كه نمرات بالاتر مبين عملكرد جنسى بهتر است. سانجز سانجز و همكاران (.Y.Y.T) نسخه ترجمه شده اين مقياس را در اسيانيا روانسنجى نموده و هايايى و روايى آن راليا تأييد كردند، ميزان بايايى به روش آزمون باز آزمون با

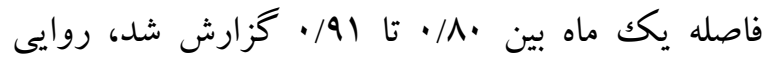

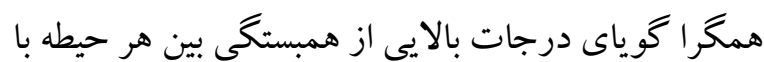
كل و روايى افتراقى گوياى تفاوت معنادار بين دو گروه افراد سالم و افراد داراى اختلال شخصيت خودشيفته بود

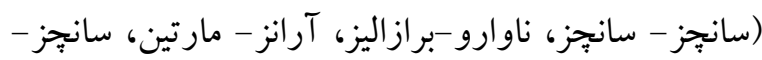

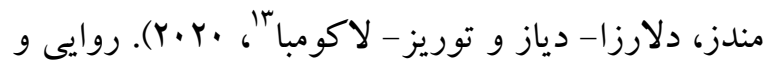
يايايى نسخه فارسى اين مقياس در ايران در مطالعه آقاو و

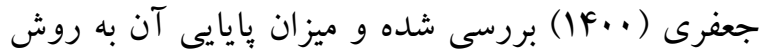

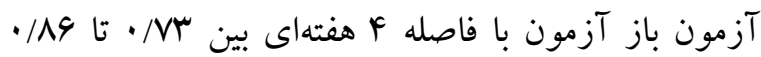
كزارش شد و به تأييد رسيد (آقاو جعفرى، ..1F).

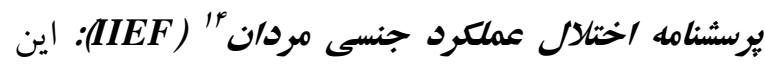
يرسشنامه در سال 1997 توسط روزن و همكاران براى سنجش عملكرد جنسى مردان در ها حوزه مستقل؛ ميل

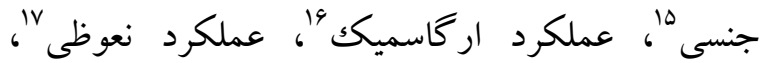

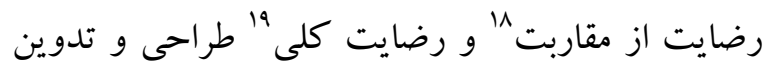
شد. اين برسشنامه داراى ها سؤال است كه در طيف

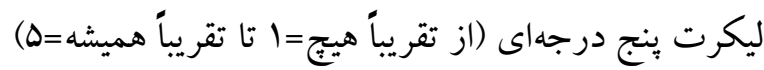

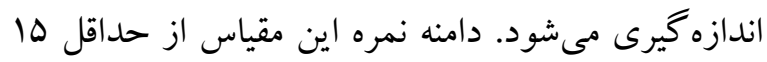

13- Sanchez-sanchez, Navarro-Brazalez, Arranz-Martin, SanchezMendez, de la Rosa-Diaz \& Torres-Lacomba

14- International Index of Erectile Function

15 - Erectile Function

16. Orgasmic Function

${ }^{17}$ - Sexual Desire

${ }^{18}$ - Intercourse Satisfaction

${ }^{19}$ - Overall Satisfaction
برسشنامه جند محورى ميلون' (MCMI): اين برسشنامه در سال $19 V V$ توسط ميلون' براى مخاطبان بالاى 1 ا سال و داراى توانايى خواندن و حداقل سواد كلاس هشتم طراحى و تدوين شد. اين برسشنامه خود اظهارى داراى IVD يرسش است كه بهصورت بلى اخير اندازه گيرى مى -

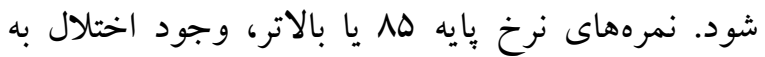

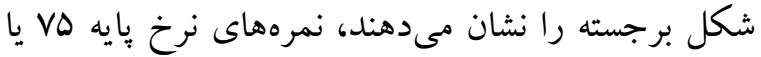

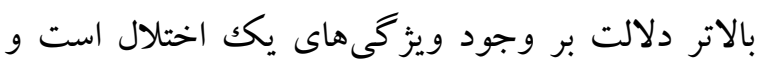
نمرههاى نرخ بايه .9 يا بالاتر تو صيف شخصيت فردى را نشان مىدهد كه نمره خام فرد از •ه درصد افراد بالاتر است. استين و همكاران (I.Y.Y) نسخه ترجمه شده اين مقياس را در يُوهشى مورد استفاده قرار داده و پايايى و روايى آن را تأييد كردند؛ ميزان آلفا كرونباخ در اين

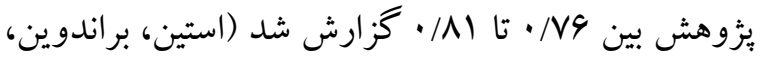

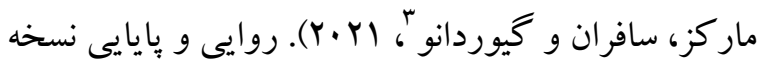
فارسى اين مقياس در ايران در مطالعه محمدى و همكاران

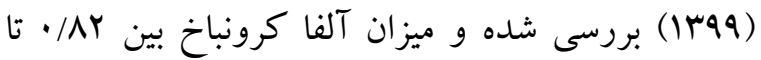

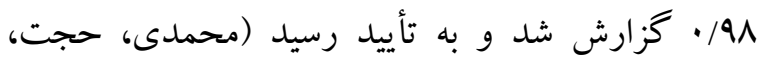
مصطفوى، خالقى، هشيارى و همكاران، 9941).

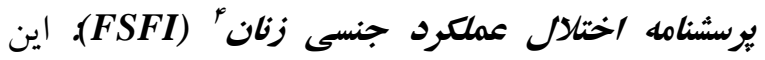

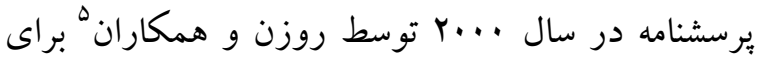

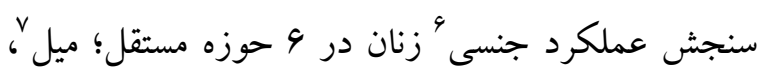

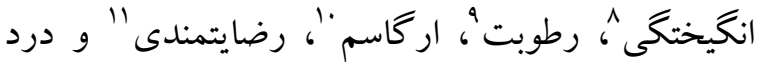
جنسى" طراحى و تدوين شد. اين برسشنامه داراى 19

\footnotetext{
- Millon Clinical Multiaxial Inventory III

2 - Millon

3 - Eastin, Brandwein, Marks, Safran \& Giordano

${ }^{4}$ - Female Sexual Function Index

5 - Rosen \& et al

6- Sexual Function

7- Desire

8 - Arousal

9 - Lubrication

10. Orgasm

11- Satisfaction

12 - Pain
} 
و در زنان ·ل نفر (س/r/ درصد) مجرد، ب نفر (9/V) درصد) متأهل بودند. در مردان IV نفر (هN/9 درصد) ليسانس، 1 نفر (rV/9 درصد) فوقليسانس و r نفر (F/ 1.

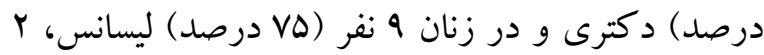
نفر (19/V درصد) فوقليسانس و ا نفر (N/N درصد) دكترى داشتند. در گروه افراد سالم ميانگين سنى مردان MF/AT \pm N/IYF NF N/9YV

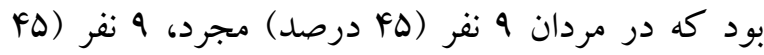
درصد) متأهل و Y نفر (•ا درصد) مطلقه و در زنان Ir نفر ( •4 درصد) مجرد و ^ نفر (·F درصد) متأهل بودند. در مردان 9 نفر (·r درصد) ليسانس، لا نفر (هه درصد) فوقليسانس و r نفر (ها درصد) دكترى و در زنان Vفر نفر

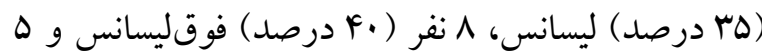
نفر (هr درصد) د كترى داشتند. ميانگين و انحراف معيار نمرههاى متغيرهاى يزّوهش در دو كروه افراد داراى اختلال شخصيت خودشيفته و افر اد سالم به تفكيك زن و و مرد در جدول ال ارائه شده است.
تا حداكثر VD است كه نمرات بالاتر مبين عملكرد جنسى

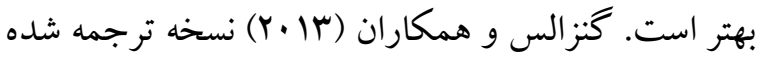
اين مقياس را در برزيل روانسنجى نموده و يايايى و روايى آن را تأييد كردند، ميزان بايايى به روش آزمون باز آزمون

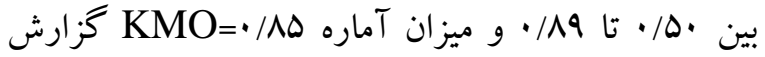
شد (كنزالس، استيز، ويتكويف، ساميايودومارا، آلبريج، كاردوسو و دو كاروالهو، سا•Y). در ايران بابازاده و همكاران (1\%99) انسجام درونى برسشنامه را توسط ضريب آلفا كرونباخ بين /9Y • تا MM/• بدست آوردند و روايى همخرا را از طريق محاسبه ضريب همبستگى شاخص بينالمللى عملكرد نعوظى با مقياس عملكرد

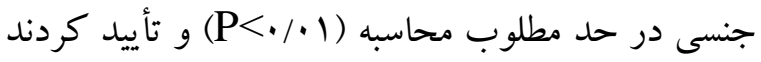

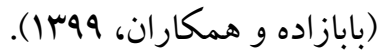

\section{يافتهها}

در گروه افراد داراى اختلال شخصيت خودشيفته ميانخين

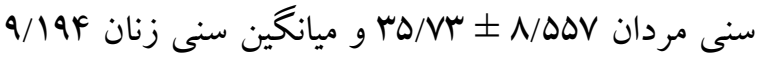

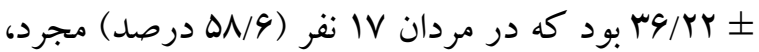
I انفر (rV/q درصد) متأهل و ا نفر (T/Y درصد) مطلقه

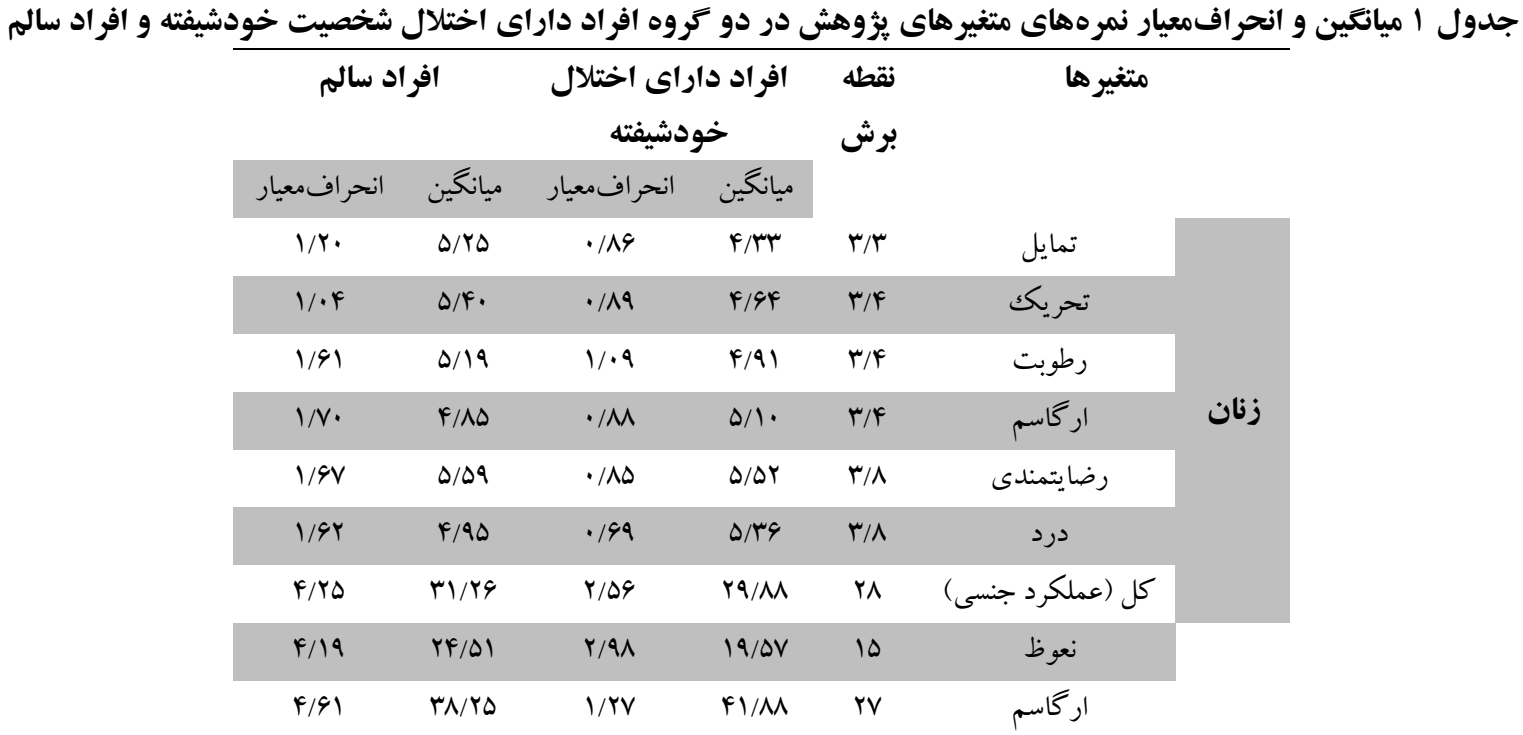




\begin{tabular}{|c|c|c|c|c|c|}
\hline $9 / 01$ & M/91 & $F / Y V$ & $r \Delta / f^{\prime}$ & 10 & رضايت جنسى \\
\hline $9 / 99$ & $M F / F F$ & $r / r q$ & $\mid r / \Delta \lambda$ & r. & تمايل \\
\hline $1 \cdot 119$ & |r|r. & $q / \wedge \Delta$ & $11 \cdot 101$ & $1 \cdot r$ & كل (عملكرد جنسى) \\
\hline
\end{tabular}

بالاتر از نقطه برش بود. در ادامه به منظور بررسى نرمال

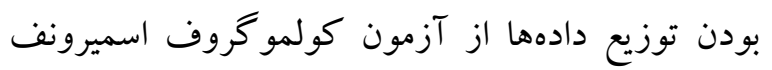

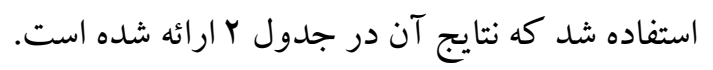

همانطوركه در جدول ا مشاهده مىشود هم در گروه

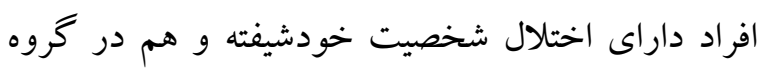

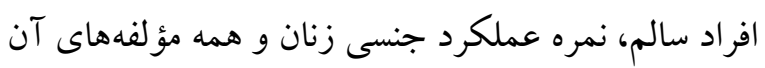

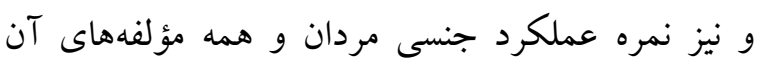

\begin{tabular}{|c|c|c|c|c|c|}
\hline \multicolumn{2}{|c|}{ افر اد سالم } & \multicolumn{2}{|c|}{ افراد داراى اختلال } & \multirow{2}{*}{\multicolumn{2}{|c|}{ متغيرها }} \\
\hline سطح معنىدارى & مقدار Z & سطح معنى دارى & Z مقدار Z & & \\
\hline • &.$/ 191$ & . /1F9 & $\cdot / r I 1$ & 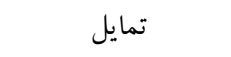 & \multirow{7}{*}{ 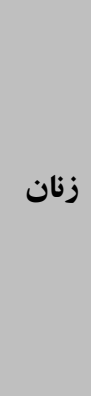 } \\
\hline$\cdot / r \cdots$ & $\cdot / \mathrm{Fr}$ & $\cdot / r \ldots$ &.$/ 1 F q$ & تحريك & \\
\hline$\cdot / r \ldots$ & $\cdot / 1 \Delta V$ & $\cdot / r \cdot \cdot$ &.$/ 1 \Delta F$ & رطوبت & \\
\hline$\cdot / r \ldots$ & $\cdot / 1 \cdot v$ & $\cdot / \cdot \Delta r$ & $\cdot /$ TAF & اركاسم & \\
\hline$\cdot / 491$ &.$/ 19$ & $\cdot / r \cdot$ &.$/ 19 r$ & رضايتمندى & \\
\hline$\cdot / r \ldots$ &.$/ 10$ &.$/ \cdot \Delta r$ & $\cdot / Y F I$ & ن مرد & \\
\hline$\cdot / r \cdots$ & $\cdot / 111$ & $\cdot / l \Delta V$ & $\cdot / r \cdot 9$ & كل (عملكرد جنسى) & \\
\hline$\cdot 1 \cdot 19$ &.$/ 1 \wedge$ & $\cdot / \cdot \Delta \Delta$ & $\cdot / M Y$ & 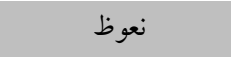 & \multirow{5}{*}{ مردان } \\
\hline$\cdot / r \ldots$ & $\cdot / \mathrm{Fr}$ & $\cdot / r \ldots$ & .1119 & اركاسم & \\
\hline$\cdot / r \ldots$ &.$/ I F$. & $\cdot / r \cdots$ & .1 .99 & رضايت جنسى & \\
\hline$\cdot / Y \cdots$ & $\cdot / \cdot 94$ & $\cdot / \cdot \Delta r$ &.$/ I V r$ & تمايل & \\
\hline$\cdot / r \cdots$ & $\cdot / 1 \mu \wedge$ &.$/ \cdot \Delta F$ &.$/ I V \wedge$ & كل (عملكرد جنسى) & \\
\hline
\end{tabular}

از متغيرها در دو گروه افراد داراى اختلال شخصيت

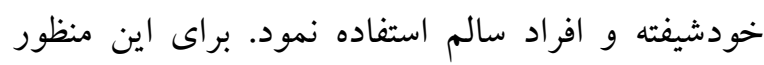

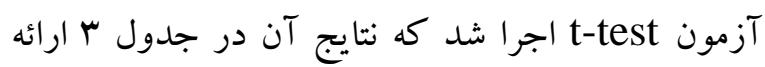

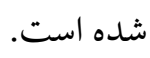

همانطور كه در جدول r مشاهده مى شود سطح معنادارى آزمون نرماليتى كلمو گروف اسميرنوف براى تمام متغيرها

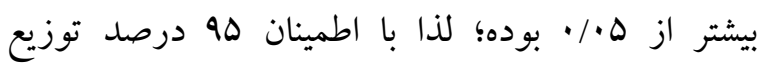

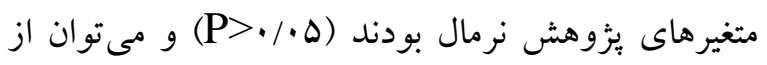

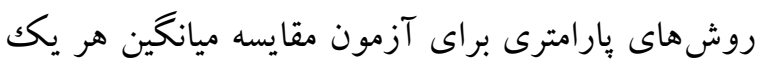

جدول ب نتايج آزمون t-test دو كروه مستقل

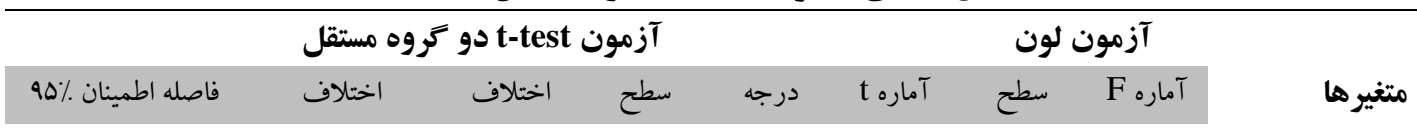




\begin{tabular}{|c|c|c|c|c|c|c|c|c|c|c|}
\hline بالا & يائين & انحر اف معيارها & ميانگينها & معنادارى & آزادى & & معنادارى & & & \\
\hline l/Vrd & .1 .91 & $\cdot / F \cdot \cdot$ & $\cdot / 91 \mathrm{~V}$ &.$/ \cdot r q$ & $r$. & Y/YAQ & $\cdot /$ TFD & $1 / F \cdot V$ & تمايل & \\
\hline $1 / 0 \cdot r$ & 每 & . Mar & . Var &.$/ . F F$ & $\mu$. & $r / l \cdot r$ & $\cdot / 9 \cdot r$ &.$/ \cdot 10$ & تحريك & \multirow{6}{*}{ زنان } \\
\hline $1 / 490$ & $-\cdot / V 99$ & . /Ora & - / TAF &.$/ \Delta 9 \Delta$ & $r$. & - /OrV & $\cdot / \cdot \mathrm{W}$ & T/YFV & رطوبت & \\
\hline .1919 & $-I / I A F$ & $\cdot / F \Delta \Lambda$ & $-\cdot / Y F V$ & - /DQF & $r 9 / 91 r$ & $-\cdot / \Delta r q$ &.$/ .19$ & G/IVr & ارغاسم & \\
\hline$\cdot / 91 \mathrm{~V}$ & $-\cdot|A F|$ & . / FFV & $\cdot / \cdot v r$ & $\cdot / A V \mid$ & $r q / F V F$ &.$/ 194$ & $\cdot \cdots \wedge$ & V/q4q & رضايتمندى & \\
\hline . fro & $-1 / r a f$ & $\cdot / f I f$ & $-\cdot / 419$ & •/MYV & rV/VQD & $-\cdot / 999$ &.$/ \cdot 1 r$ & $V / M I r$ & درد & \\
\hline$\varphi / 10 \varphi$ & $-1 / 4 \cdot r$ & $|/ / 49|$ & I/TVG & • & r. & $1 / \cdot 11$ & $\cdot / \cdot 9 V$ & r/ard & كل & \\
\hline$V / \cdots F$ & r/MI & I/.YF & F/QFY & $\cdot \cdots$ & FV & F/AYr & $\cdot / \cdot \sqrt{ } 9$ & $r / Y \wedge 1$ & نعوظ & \multirow{5}{*}{ مردان } \\
\hline$-1 / F Y V$ & - - - & $1 / .09$ & $-r / 9 r$. & •r & $r y / \cdot 1$. & -r/Frg & $\cdot / \cdot 1$ & $11 / 4 \cdot 1$ & اركاسم & \\
\hline $1 / 94 A$ & $-F / \Lambda Y$. & $1 / 90 \mathrm{~V}$ & $-1 /$ fra & س & $r \cdot / l F V$ & $-\cdot / 1999$ &.$/ \cdot 1 F$ & G/FVG & رضايت جنسى & \\
\hline TF/YY. & IV/Faq & 1/94. & $r \cdot / \wedge \Delta \wedge$ & $\cdot \cdots$ & YI/AD. & $|r / A V|$ & $\cdot / \cdots$ & $r q / F \mid F$ & تمايل & \\
\hline rq/ror & $10 / 11 V$ & Y/VFA & $r \cdot / N M F$ & $\cdot \cdots$ & $r q / r \cdot q$ & V/DFD & $\cdot / \cdot 1$ & $11 / F_{A}$ & كل & \\
\hline
\end{tabular}

يثوهش حاضر با هدف مقايسه ميزان شيوع اختلالات عملكرد جنسى در مبتلايان به اختلال شخصيت خودشيفته و افراد سالم انجام شد. نتايج بثوهش حاضر گوياى آن بود كه هم در افراد داراى اختلال شخصيت خودشيفته و هم در افراد سالم، نمره عملكرد جنسى زنان و مردان همه مؤلفههاى آنها بالاتر از نقطه برش بود و در زنان عملكرد جنسى و مؤلفهاى رطوبت، اركاسم، رضايتمندى و درد و در مردان مؤلفه رضايت جنسى در دو گروه افراد داراى اختلال شخصيت خودشيفته و افراد سالم تفاوت معنادارى نداشتند. در عين حال در زنان مؤلفههاى تمايل و تحريك و در مردان عملكرد جنسى و مؤلفه هاى تمايل و نعوظ در افراد سالم بيشتر از افراد داراى اختلال شخصيت

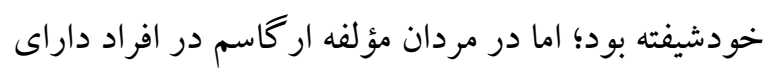
اختلال شخصيت خودشيفته بيشتر از افراد سالم بود. با توجه به آن كه تاكنون يُوهشى در خصوص بررسى ميزان شيوع اختلال عملكرد جنسى در افراد با اختلال

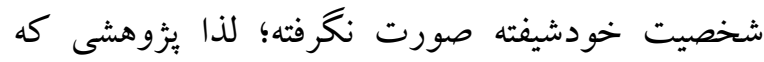
بتوان نتايج آن را بلصورت مصداقى با نتايج يثوهش
همانطور كه در جدول r مشاهده مىشود براكندكى عملكرد جنسى زنان و مؤلفههاى تمايل زنان، تحريك، رطوبت و نعوظ در دو گروه افر اد داراى اختلال شخصيت

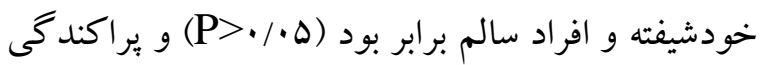

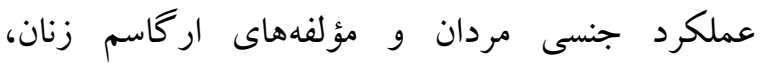
رضايتمندى، درد، ارگاسم مردان، رضايت جنسى مردان و تمايل مردان در دو گروه افراد داراى اختلال شخصيت خودشيفته و افراد سالم برابر نبود (ه (P</ P). همجنين جدول ب نشان مىدهد كه عملكرد جنسى زنان و مؤلفه هاى رطوبت، ار كاسم زنان، رضايتمندى، درد و رضايت جنسى مردان در دو گروه افراد داراى اختلال شخصيت خودشيفته و افراد سالم معنادار نبود (ه •/P> (P)، عملكرد جنسى مردان و مؤلفههاى تمايل زنان، تحريك،، نعوظ و تمايل مردان در افراد سالم بيشتر از افراد داراى اختلال شخصيت خودشيفته بود (ه•/P<) و ار كاسم مردان در افراد داراى اختلال شخصيت خودشيفته بيشتر از افراد

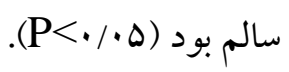


خشم دهانى دانست كه از محروميت هيجانى ناشى از وجود يك جهره مادرانه بى تفاوت و بدخواه حاصل مى شود. خشم دهانى به نظر مىرسد مىتواند تبيينى براى نحوه اركاسم و ترجيح تحريك دهانى توسط شريك جنسى باشد. افراد داراى اختلال شخصيت خودشيفته تمايل دارند كه روابط جنسى و احساسى را به عنوان

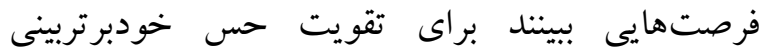

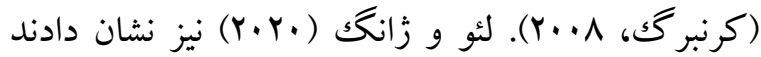
كه افراد مبتلا به اختلال شخصيت خودشيفته در بيى يافتن شر كاى جنسى صرفاً به جهت ارضاء نيازهاى خود مى باشند و در اين راستا از داشتن شر كاى جنسى متعدد ابايى ندارند. كويرتزمايدان (Y.IV) به از كرنبر گك نقل مى كند كه اكرجه خصيصه انخيزشى مركزى در اختلالهاى شديد شخصيت، رشد و تحول برخاشخرى آسيبشناختى است، آسيب مسلط اختلالهاى شخصيت سطوح بالا يا نوروتيك،، آسيبشناسى مسائل جنسى است. اين اختلالها تماماً تظاهرى از برخى حالتهاى بازدارىهاى جنسى مرتبط با تعارضهاى ادييال و صفات شخصيتى آسيبشناختى است كه تحت سلطه كنشورزى تعارضهاى اديِال كناه ناخود آكاه معطوف به تكانه هاى جنسى دوران

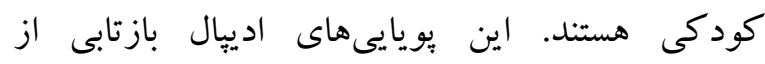
برانگيختخى روابط ابزه درونى است كه بهصورت نا باني هوشيار با خياليردازىهاى كودكى در مورد غلبه و كاميابى جنسى در ارتباط با يكك يا هر دو والد مرتبط هستند. تكانه هاى جنسى معطوف شده به سمت والدين به همراه آرزوها و خياليردازىهاى مرتبط با آن غيرقابل يذيرش در نظر گرفته مىشوند و در نتيجه سركوب شده باقى مى مانند و بازدارىهاى جنسى و منش انعطافنايذير شخصيت نورو تيكك را ايجاد مى كنند. به همين علت براى
حاضر مقايسه نمود وجود ندارد در عين حال نتايج يُزوهش حاضر با نتايج يُّوهشهاى؛ دى، تونسند و

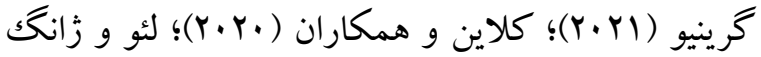

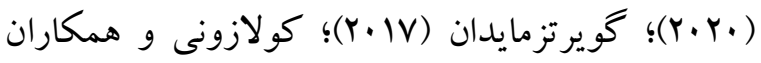
(Y.IV) و ذبيحىفرد و صلاحيان ( IF...) كه بهطور كلى (I) اشاره كردند كه كيفيت زندگى جنسى افراد داراى اختلال شخصيت خودشيفته داراى اختلالاتى در كاركرد عملكرد جنسى هست، همسو بود.

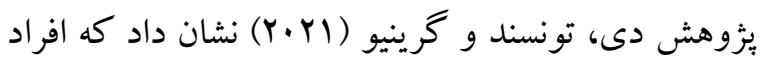
مبتلا به اختلال شخصيت خودشيفته در برقرارى ارتباط ميان فردى دجار مشكلاتى مىشوند من جمله روابطى كه با تجربيات جنسى مرتبطاند و اين مسئله زمينه ساز اين واقعيت است كه افراد مبتلا به اختلال شخصيت خودشيفته ممكن است احساس كنند كه فقط از سوى افراد استثنائى و خاص درك مىشوند و مىبايست تنها با آنها مراوده داشته باشند به طورى كه در برقرارى رابطه دوستانه و خصوصاً رابطه جنسى بسيار مشكل بسند هستند. هم:جنين كلاين و همكاران ( • (Y.r) نشان دادند كه روابط بين افراد مبتلا به اختلال شخصيت خودشيفته سطحى است و در روابطشان بهره كشى مى كنند، انتظارات زياده از حد دارند و نسبت به ديخران همدلى نشان نمىدهند، حال آن كه فقدان جنين همدلى در روابط عامل مهمى در ابتلاى بيشتر به اختلال در ميل جنسى ايشان خواهد بود. به نظر مىرسد فقدان دركى جامع روابط بين فردى در افراد داراى اختلال شخصيت خودشيفته عامل قابل تأملى در مشكلات جنسى و شيوع بالاى اختلالات عملكرد جنسى باشد.

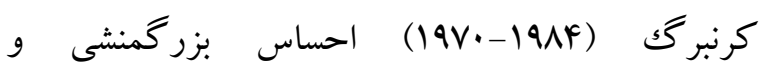
استثمار گرى شخصيت خودشيفته را به عنوان نشانهاى از 
مؤلفههاى تمايل و تحريك و در مردان داراى اختلال شخصيت خودشيفته شيوع اختلال در عملكرد جنسى و مؤلفههاى تمايل و نعوظ بيشتر از افراد سالم بود. يزوهش حاضر با محدوديتهايى نيز همراه بود كه از آن جمله

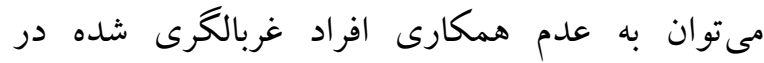
خصوص ياسخ به برسشنامههاى عملكرد جنسى به دليل تابو بودن اين سازهها در جامعه اشاره كرد. همجِنين فقدان همدلى افراد غربالكرى شده در فرآيند ياسخدهى به برسشنامههاى اختلال عملكرد جنسى نيز اخلال ايجاد كرد به كونهاى كه فقط يككسوم از افراد داراى تشخيص اختلال شخصيت خودشيفته به يرسشنامهاى اختلال عملكرد جنسى بِاسخ دادند.

\section{سياسگزارى}

بر خود لازم مىدانيم از تمام افرادى كه با مشاركت خود در اين بثزوهش ما را يارى كردند، تشكر و قدردانى

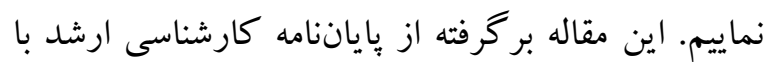
كد ه.."r مصوب دانشگاه آزاد اسلامى واحد علوم و تحقيقات با كد كميته اخلاق SRIAU.129.23 است. همجنين بر حسب مدار ك،، در اين مقاله هيجِكونه تعارض منافعى بين نويسند گان وجود ندارند.

\section{References}

Agha PH, Jafari M. (2021). Psychometric properties of Iranian version of female sexual function index. Jundishapur Sci Med J. 10, 345-354. (In Persian)

Babazadeh S, Habibi M, Gohari-Derakhshande N. (2020). Study of Psychometric Properties of the International Index of Erectile Function (IIEF) in Substance Dependent Men. Joumal of Applied Psychology. 14, 457-435. (In Persian)
افراد نوروتيكك برخوردارى از لذت جنسى با فرد مورد

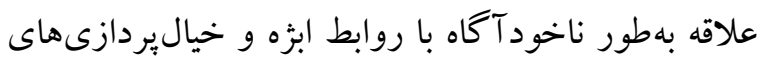
وابسته به آن سر كوب شدهاند، مرتبط مىشود. نوروتيك ها به طريقى از يكيارجّهازى شهوت و شفقت اجتناب مى كنند. عكس موقعيتى كه در مورد اختلالهاى شخصيت نوروتيك توصيف شد، در اختلالهاى شديد شخصيت جايى كه تعارضهاى ابتدايى در ارتباط با يرخاشگرى آسيبشناختى وجود دارد، نوع رفتار جنسى را برخاشخرى تعيين مى كند. كولازونى و همكاران (Y.IV) در بزّوهش خود نشان دادند كه دل مشغولى افراد مبتلا به اختلال شخصيت خودشيفته در روابط جنسى آن است كه عملكردشان در رابطه جنسى تا جه اندازه خوب و مطلوب است و اغلب با فريبندگى زياد همواره به دنبال تحسين و ستايش شدن از

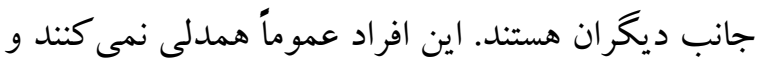
در تشخيص دادن اميال، تجربيات ذهنى و احساسات ديخران مشكل دارند و روابط ميان فردىشان معمولاً به علت مشكلات ناشى از سزاوارى، نياز به تحسين و بى توجهى به حساسيتهاى ديخران معيوب است. همجنين

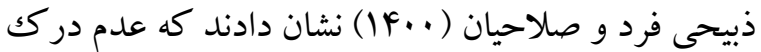
و همدلى در افراد داراى اختلال شخصيت خودشيفته منجر به بروز مشكلات و سوء تفاهمهايى در روابط جنسى اين افراد شده كه مىتواند عاملى مهم و تعيين كننده در تمايل بيشتر اين افراد به خود ارضائى در مقايسه با جمعيت بهنجار است.

\section{نتيجه كيرى}

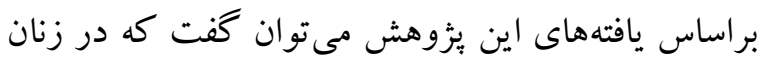
داراى اختلال شخصيت خودشيفته شيوع اختلال در 
Barabadi A, Agah Z, Akrami R. (2018). Prevalence of Sexual Dysfunction and ralated psychological factors in women of Sabzevar. Joumal of Sabzevar University of Medical Sciences. 25, 101-109. (In Persian)

Casale S, Banchi V. (2020). Narsisssim and problematic social media use: A systematic literature revieiwe, Addictive Behaviors Repotrts. 11, 202-211.

Collazzoni A, Ciocca G, Limoncin E, Manucci C, Mollaioli D, Di Sante S, Jannini EA. (2017). Mating Strategies and Sexual Functioning in Personality Disorders: AComprehensive Review of Literature. Sexual Medicine Reviews. 5, 414-428.

Day NJS, Townsend ML, Grenyer BFS. (2020). Living with pathological narcissism: a qualitative study. bord personal disord emot dysregul. 7, 19.

Decaro SP, Di Sarno M, Anzani A. (2021). Narcissistic Personality Traits and Sexual Dysfunction in Women. J Sex Med. 18, 1891-1898.

Dimaggio G. (2021). Treatment principles for pathological narcissism and narcissistic personality disorder. Joumal of Psychotherapy Integration. Advance online publication.

Donald W, Black MD. (2021). A c;inical approach to pharmacotherapy for personality. Current Psychiatry. 20, 26-32.

Eastin SM, Brandwein DR, Marks DR, Safran, R, Giordano K. (2021). The MCMI-IV: a new normal quartet for parental fitness litigants. Journal of personality assessment. 23.

French JH, Shrestha S. (2019). Personality Disorder. In StatPearls. Treasure Island (FL): Stat Pearls Publishing.

Gewirtz-Maydan A. (2017). Why do narcissistic individuals engage in sex? Exploring sexual motives as a mediator for sexual satisfaction and function. Personality and Individual Differences. 105, 7-13.

Gonzales AI, Sties WS, Wittkopf PG, Sampaio de Mara L, Ulbrich AZ, Cardoso FL, De Carvalho T. (2013). Validation of the International Index of Erectile Function (IIFE) for Use in Brazil. Arq Bras Cardiol. 101, 17682.

Kernberg O. (2008). Aggressivity, Narcissism, and SelfDestructiveness in the Psychotherapeutic Rela: new D evelopments in the Psychopathology and Psychotherapy of Severe Personality Disorders. Yale University Press.

Klein V, Reininger KM, Briken P, Turner D. (2020). Sexual narcissism and its association with sexual and well-being outcomes. Personality and Individual Differences. 152, 109557.

Liu Y, Zheng L. (2020). Relationships between the Big Five, narcissistic personality traits, and online sexual activities. Personality and Individual Differences. 152, 109-119.

Martin J, Walcott G, Clarke TR, Barton EN, Hickling FW. (2013). The prevalence of personality disorder in a general medical hospital population in Jamaica. West Indian Medical Journal. 62, 463-467.

Martin S, Graziani P, Del-Monte J. (2021). Insight's level in borderline personality disorder, questioning consciousness. Joumal of Affective Disorders Reports. 3, 100045.

McCabe MP, Sharlip ID, Lewis R, Atalla E, Balon R, Fisher AD, Segraves RT. (2016). Incidence and prevalence of sexual dysfunction in women and men: a consensus statement from the Fourth International Consultation on Sexual Medicine 2015. The journal of sexual medicine. 13, 144-152.

Miller JD, Widiger TA, Campbell WK. (2010). Narcissistic personality disorder and the DSMV. Joumal of Abnormal Psychology. 119, 640.

Mohammadi MR, Hojjat SK, Mostafavi SA, Khaleghi A, Hooshyari Z, Ahmadi N, Kaviani F, Norozi Khalili M. (2021). Parents' Personality Disorder as Predictor of Substance Use Disorder in Children and Adolescents. Arch Iran Med. 24, 478-486. (In Persian)

Nasehi AA, Raisi F, Ghaeli P, Amini M, Yahyavi ST, Arabkheradmand J, ... \& Abdi F. (2017). Prevalence of sexual dysfunction among general population of Iran: A systematic 
review. Iranian Joumal of Psychiatry and Behavioral Sciences. 11, e7643. (In Persian)

Nenadic I. (2021). Narcissistic Traits and Executive Functions. Front. Psychol. 12, 707887.

Ronningstam E. (2016). Pathological Narcissism and Narcissistic Personality Disorder: Recent Research and Clinical Implications. Current Behavioral Neuroscience Reports. 3,34-42.

Rostami Dovom M, Ramezani Tehrani F. (2020). A Review of the Relationship between Obesity and Some Sexual Dysfunction in Men and Women. Iranian Joumal of Endocrinology and Metabolism. 21, 319-328. (In Persian)

Sanchez-sanchez B, Navarro-Brazalez B, ArranzMartin B, Sanchez-Mendez O, de la RosaDiaz I, Torres-Lacomba M. (2020). The female sexual function index: transculturally adaptation and psychometric validation in Spanish woman. Int J Environ Res Public Health. 17,994.

Skodol AE, Morey LC, Bender DS, Oldham JM. (2015). The alternative DSM-5 model for personality disorders: a clinical application. American Joumal of Psychiatry. 172, 606-613.

Williams R, Casini MP, Moselli M, Frattini C, Ronningstam E. (2021). The Road from Pathological Narcissism to Suicidality in Adolescence: An Empirical Study. Int. J. Environ. Res. Public Health. 18, 9761.

Zabihi Fard Z, Salahian A. (2021). Assessing the sexuality of people diagnosed with narcissistic personality disorder. Fifth National Conference on Social Science, Psychology and Educational Sciences. Jiroft. (In Persian) 